\title{
We need to talk: clinical competency committees in the key of c(onversation)
}

\author{
Paul A. Hemmer ${ }^{1}$ William F. Kelly ${ }^{1}$
}

Published online: 23 May 2017

(c) The Author(s) 2017. This article is an open access publication.

James Suroweicki's book, The Wisdom of Crowds [1], provided examples of how diverse, independently deciding individuals make some decisions and predictions better than any individual, even an expert one. However, there have been epic failures where group dynamics derail decisionmaking and crowds become herds.

Over the past decades, there has been a steady movement towards competency-based medical education accompanied by assessment programs emphasizing the judgment of experts in promotion and progress decisions [2]. While competency committees are not new in undergraduate medical education [3] or graduate medical education [4], they are now required of all residency training programs in the US accredited by the Accreditation Council for Graduate Medical Education (ACGME) [5] and will soon be required in training programs in Canada [6]. What is not well understood is how members of a clinical competency committee (CCC) reach a judgment or conclusion. In their article, Chacine et al. report on their synthesis of literature on group decision-making which yielded three orientations (schema, constructivist, and social influence) that are within a context of 'moderators' (moderating influences) that can help to frame an approach to examining how CCC decisions are made.

Why is the 'how' an important question to answer? Simply put, CCCs represent a visible commitment to the im-

\section{Disclaimer The views expressed in this paper are those of the authors and do not necessarily reflect the views of the Uniformed Services University, the Department of Defense, or other federal agencies.}

Paul A. Hemmer

paul.hemmer@usuhs.edu

1 Department of Medicine, Uniformed Services University of the Health Sciences, Bethesda, MD, USA portance of conducting evaluation, reaching judgments, and ensuring fairness to multiple stakeholders - to society, to teachers, and to trainees. Because the work of the CCC is at the very core of the profession of those involved in educational training programs, if we can illuminate and elucidate the elements of how decisions are made, we may develop insight into what makes for highly functioning and effective committees. In short, knowing how a committee arrives at a decision is the first step towards ensuring it is making the best one.

\section{Conversation is the key}

Based on our own 30-year experience of placing conversation at the centre of a program of assessment, we believe that the conversation itself holds the key to understanding CCC decisions [3, 7-16]. Conversation 'is a progression of exchanges' among participants; each participant changes internally as a consequence of conveying and generating knowledge [17]. It is here that Gordon Pask's Conversation Theory is relevant $[17,18]$. Coming from the field of cybernetics, conversation theory addresses how learning takes place through conversation. At the risk of oversimplification, a series of steps has been summarized as: opening a channel (beginning with a message); commit to engage (engagement on the part of those in the conversation); construct meaning (through an interchange, those involved begin to construct meaning); evolve (participants are in some way changed); converge on agreement (and this includes the ability to 'teach back'); act or transact (one or more participants agree to do something as a result) [17].

A central feature of conversation theory is reaching agreement over an understanding' (Converge on Agreement) - in the work of the CCC, this would be the pro- 
cess by which the members reach a decision, consensus, or agreement over the understanding of 'competence'. The formulation of 'competence' might vary depending on the frame of reference (e. g., ACGME, CANMEDS, Entrustable Professional Activities, Reporter-Interpreter-Manager-Educator) but that is the shared understanding which is served by the conversation. While conversation theory would seem most readily applicable to the Constructivist orientation proposed by Chahine et al., it is also relevant to the other orientations. The requirement for the CCC is a recognition of the power of conversation to clarify, calibrate, coordinate, and collaborate. Conversation changes participants in meaningful ways, and understanding how they are changed should be part of the exploration of CCC decision-making.

\section{How do CCCs reach consensus? It probably depends}

The authors recognize that the orientations they propose are not mutually exclusive and that it is probable that all orientations are likely to be used, to one degree or another, in the conversations to reach a consensus about trainees - which orientation predominates (if one does) probably depends on the trainee, the CCC members, and the context. In many ways, this is analogous to competence in patient care that involves factors related to the physician, patient, and encounter [19].

A competent competency committee must understand the judgments they make, the feedback an individual trainee needs on their growth to independence, and recognize contextual factors that can impact the group's decision. Awareness of such 'moderators' and decision-making pitfalls is essential and one more benefit of examining how decisions are made.

CCC members, typically program faculty and teachers themselves, are likely going to be 'meaningfully idiosyncratic' in how they process information and reach a judgment [20]. While this may lead to voicing differing views, it likely represents more 'signal' about the trainee than 'noise' from the CCC process.

Resources are likely to be a major 'moderator', including financial, adequate faculty training and expertise, and especially time, as longer discussions usually produce better learner feedback. Additionally, the complexity and detail of the competency frameworks themselves (e.g., ACGME, CANMEDS) may also impact decision-making, as could the type, size, and scope of the training program.

Pitfalls of group decision-making include reduced efficiency, a diffusion of responsibility (lack of accountability) which can lead to 'groupthink'. This is an often unconscious desire for harmony (getting along) or for conformity (deferring to leaders with greater 'psychological size'). However, prior work from nearly 20 years ago has demonstrated that groupthink or dominance by certain individuals was not evident in CCCs at the undergraduate [3] or graduate [4] level in medical education - what mattered was the information being discussed. Having the most junior person speak first and the committee chair speak last (if at all) may help to limit groupthink or individual dominance. Another scenario, 'group polarization' or 'risk shifting', is related to this and has occurred when the group's decision is much more extreme than if made by its individual members. 'Shared information bias' occurs when members spend all of their time discussing a portion of information they all have and ignore more important information available to a subset of the members. Use of 'touchstones' or ground rules for professional discussions, and reflection and feedback after CCC meetings may improve the process.

\section{Next steps}

In seeking to address the how of decision-making by members of a CCC, there may be challenges in identifying CCCs to study, such as whether to try to select examples of effective and less effective committees, how to define that effectiveness (which committees made the 'best' decisions), and establishing the trustworthiness of the qualitative information likely to be central to this type of study. Nevertheless, by seeking to understand the how, we move forward in our commitment to fairness to society, teachers, and trainees. The authors have suggested a framework to begin the conversation about how CCCs make decisions.

Acknowledgements The authors wish to thank Dr. Louis N. Pangaro for his mentorship and conversations.

Open Access This article is distributed under the terms of the Creative Commons Attribution 4.0 International License (http:// creativecommons.org/licenses/by/4.0/), which permits unrestricted use, distribution, and reproduction in any medium, provided you give appropriate credit to the original author(s) and the source, provide a link to the Creative Commons license, and indicate if changes were made.

\section{References}

1. Surowiecki J. The wisdom of crowds: why the many are smarter than the few and how collective wisdom shapes business, economies, societies, and nations. New York: Anchor Books; 2004, p 336.

2. van der Vleuten CP, Schuwirth LW. Assessing professional competence: from methods to programmes. Med Educ. 2005;39:309-17.

3. Gaglione MM, Moores L, Pangaro L, Hemmer PA. Does group discussion of student clerkship performance at an education committee affect an individual committee member's decisions? Acad Med. 2005;80(10 Suppl):S55-S8.

4. Williams RG, Schwind CJ, Dunnington GL, Fortune J, Rogers D, Boehler M. The effects of group dynamics on resident progress committee deliberations. Teach Learn Med. 2005;17(2):96-100. 
5. Andolsek K, Padmore J, Hauer KE, Holmboe E. Clinical competency committees. A guidebook for programs: Accreditation Council for Graduate Medical Education 2017. https://www.acgme.org/ Portals/0/ACGMEClinicalCompetencyCommitteeGuidebook.pdf. Accessed 26 Mar 2017.

6. Competence committees: A critical component of competencybased assessment. Royal College of Physicians and Surgeons of Canada. Available from: http://www.royalcollege.ca/rcsite/cbd/ competence-committee-e. Accessed 26 March 2017.

7. Hauer KE, Mazotti L, O'Brien B, Hemmer PA, Tong L. Faculty verbal evaluations reveal strategies used to promote medical student performance. Med Educ Online. 2011;16 doi:10.3402/meo.v16i0. 6354.

8. Hemann BA, Durning SJ, Kelly WF, Dong T, Pangaro LN, Hemmer PA. Referral for competency committee review for poor performance on the internal medicine clerkship is associated with poor performance in internship. Mil Med. 2015;180(4 Suppl):71-6.

9. Hemann BA, Durning SJ, Kelly WF, Dong T, Pangaro LN, Hemmer $\mathrm{PA}$. The association of students requiring remediation in the internal medicine clerkship with poor performance during internship. Mil Med. 2015;180(4 Suppl):47-53.

10. Hemmer PA, Dadekian GA, Terndrup C, Pangaro LN, Weisbrod $\mathrm{AB}$, Corriere $\mathrm{MD}$, et al. Regular formal evaluation sessions are effective as frame-of-reference training for faculty evaluators of clerkship medical students. J Gen Intern Med. 2015;30:1313-8.

11. Hemmer PA, Hawkins R, Jackson JL, Pangaro LN. Assessing how well three evaluation methods detect deficiencies in medical students' professionalism in two settings of an internal medicine clerkship. Acad Med. 2000;75:167-73.

12. Hemmer PA, Pangaro L. The effectiveness of formal evaluation sessions during clinical clerkships in better identifying students with marginal funds of knowledge. Acad Med. 1997;72:641-3.
13. Hemmer PA, Pangaro L. Using formal evaluation sessions for casebased faculty development during clinical clerkships. Acad Med. 2000;75:1216-21.

14. Lavin B, Pangaro L. Internship ratings as a validity outcome measure for an evaluation system to identify inadequate clerkship performance. Acad Med. 1998;73:998-1002.

15. Noel GL. A system for evaluating and counseling marginal students during clinical clerkships. J Med Educ. 1987;62:353-5.

16. Roop SA, Pangaro L. Effect of clinical teaching on student performance during a medicine clerkship. Am J Med. 2001;110:205-9.

17. Dubberly H, Pangaro P. What is conversation? How can we design for effective conversation? : Interactions Magazine 2009. http:// www.dubberly.com/articles/what-is-conversation.html. Accessed 24 Mar 2017.

18. Pangaro P. Cybernetics and Conversation. Available from: http:// pangaro.com/published/cyb-and-con.html. Accessed 24 March 2017.

19. Durning S, Artino AR Jr., Pangaro L, van der Vleuten CP, Schuwirth L. Context and clinical reasoning: understanding the perspective of the expert's voice. Med Educ. 2011;45:927-38.

20. Gingerich A, Kogan J, Yeates P, Govaerts M, Holmboe E. Seeing the 'black box' differently: assessor cognition from three research perspectives. Med Educ. 2014;48:1055-68.

Paul A. Hemmer MD, MPH is professor and vice chair, Educational Programs, Department of Medicine, Uniformed Services University of the Health Sciences.

William F. Kelly MD is associate professor and director, Internal Medicine Clerkship. Department of Medicine, Uniformed Services University of the Health Sciences. 